\section{DIVERSITY, DISTRIBUTION PATTERN AND SEASONAL VARIATION IN MOTH ASSEMBLAGES ALONG ALTITUDINAL GRADIENT IN GANGOTRI LANDSCAPE AREA, WESTERN HIMALAYA, UTTARAKHAND, INDIA}

Abesh Kumar Sanyal ${ }^{1}$, V.P. Uniyal ${ }^{2}$, Kailash Chandra ${ }^{3} \&$ Manish Bhardwaj ${ }^{4}$

1,2,4 Wildlife Institute of India, P.O. Box-18, Chandrabani, Dehra Dun, Uttarakhand 248001, India

${ }^{3}$ Central Zone Regional Centre, Zoological Survey of India, 168-189 Vijaynagar, Jabalpur, Madhya Pradesh 482002, India

${ }^{1}$ abesh@wii.gov.in, ${ }^{2}$ uniyalvp@wii.gov.in (corresponding author), ${ }^{3}$ kailash611@rediffmail.com, ${ }^{4}$ manish@wii.gov.in

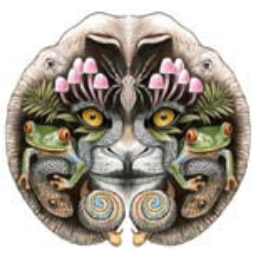

ISSN

Online 0974-7907

Print 0974-7893
Abstract: Field survey was conducted at different altitudes and landuse areas in the two protected areas, viz., Gangotri National Park and Govind National Park of Uttarkashi District, Uttarakhand, India. A total of 475 specimens of moth representing 436 morphospecies were collected using light trap method during the survey conducted between September 2008-May 2010. Preliminary findings show a decreasing diversity with increasing altitude. Subalpine areas were least diverse and subtropical areas had the highest diversity of moths. The greatest number of specimens were collected during the summer and post-monsoon period. The lunar phase had a significant effect on catch success with new moon days resulting in the largest catches and full moon days resulting in the least number of species as well as individuals. Of the thirty two species mentioned in Appendix 1, nine species are first time record from the state Uttarakhand. Four species are new record from Western Himalaya within Indian Territory, and also first time recorded from entire Himalayan landscape. As there was no previous comprehensive study on the moth diversity of Gangotri landscape area, all the 32 species described could be regarded as new record from these two protected areas.

KeyWords: Altitudinal distribution, catch success, Gangotri landscape area, moths, seasonal variability.

An inventory of biodiversity is of primary importance as part of biodiversity conservation for sustainable development, particularly in threatened and fragmented landscapes like Western Himalaya that harbours unique assemblage of flora, fauna of considerable conservation importance. In comparison with higher plants and larger animals, the inventory of insects in Western Himalayan landscape is still fragmentary and incomplete.

Recent estimates reveal the report of over 127,000 species of moths from the world, of which over 12,000 species are recorded from India (Chandra 2007). The comprehensive work on moths of different regions of Western Himalaya within the Indian Territory was mostly carried out by Hampson (1892, 1894, 1895, 1896) and Bell \& Scott (1937) in their "Fauna of British India" series and Cotes \& Swinhoe (1886) in "A catalogue of moths of India". Since then not much work has been carried out on moth fauna of Western Himalaya except Arora (1997, 2000) who had published some moth species from the Nanda Devi Biosphere Reserve, Garhwal Himalaya, Uttarakhand and Smetacek (2008) who published 887 species of moth from different elevations in Nainital District, Kumaon Himalaya, Uttarakhand. So far no comprehensive work on moth fauna in Gangotri landscape area which is an important wildlife refuge in high altitudes of Uttarakhand State has been done.

\section{Study site}

The study was conducted in two high altitude protected areas of Uttarakhand (Fig. 1) Gangotri National

DOI: http://dx.doi.org/10.11609/JoTT.o2597.3646-53 | ZooBank: urn:Isid:zoobank.org:pub:B071F0A8-BD65-41F8-B120-9FADD54BB996

Editor: Peter Smetacek, Butterfly Research Centre, Bhimtal, India

Date of publication: 26 February 2013 (online \& print)

Manuscript details: Ms \# 02597 | Received 04 October 2010 | Final received 26 November 2012 | Finally accepted 14 January 2013

Citation: Sanyal, A.K., V.P. Uniyal, K. Chandra \& M. Bhardwaj (2013). Diversity, distribution pattern and seasonal variation in moth assemblages along altitudinal gradient in Gangotri landscape area, Western Himalaya, Uttarakhand, India. Journal of Threatened Taxa 5(2): 3646-3653; doi:10.11609/JoTT.o2597.3646-53

Copyright: (C) Sanyal et al. 2013. Creative Commons Attribution 3.0 Unported License. JoTT allows unrestricted use of this article in any medium, reproduction and distribution by providing adequate credit to the authors and the source of publication.

Funding: Training Research and Academic Council (TRAC), Wildlife Institute of India.

Competing Interest: None.

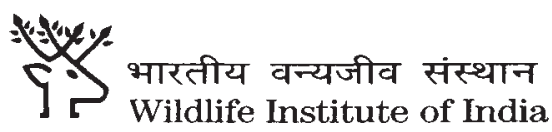

Acknowledgements: The authors are grateful to Director and Dean, Wildlife Institute of India and Director, Zoological Survey of India for guidance and support. Thanks to Uttarakhand Forest Department and field staff of Gangotri and Govind National Park for necessary permission and logistics for conducting the study. Staffs of Central Zone Regional Centre, Zoological Survey of India, Jabalpur are highly thankful for assisting during identification and literature consultation. 

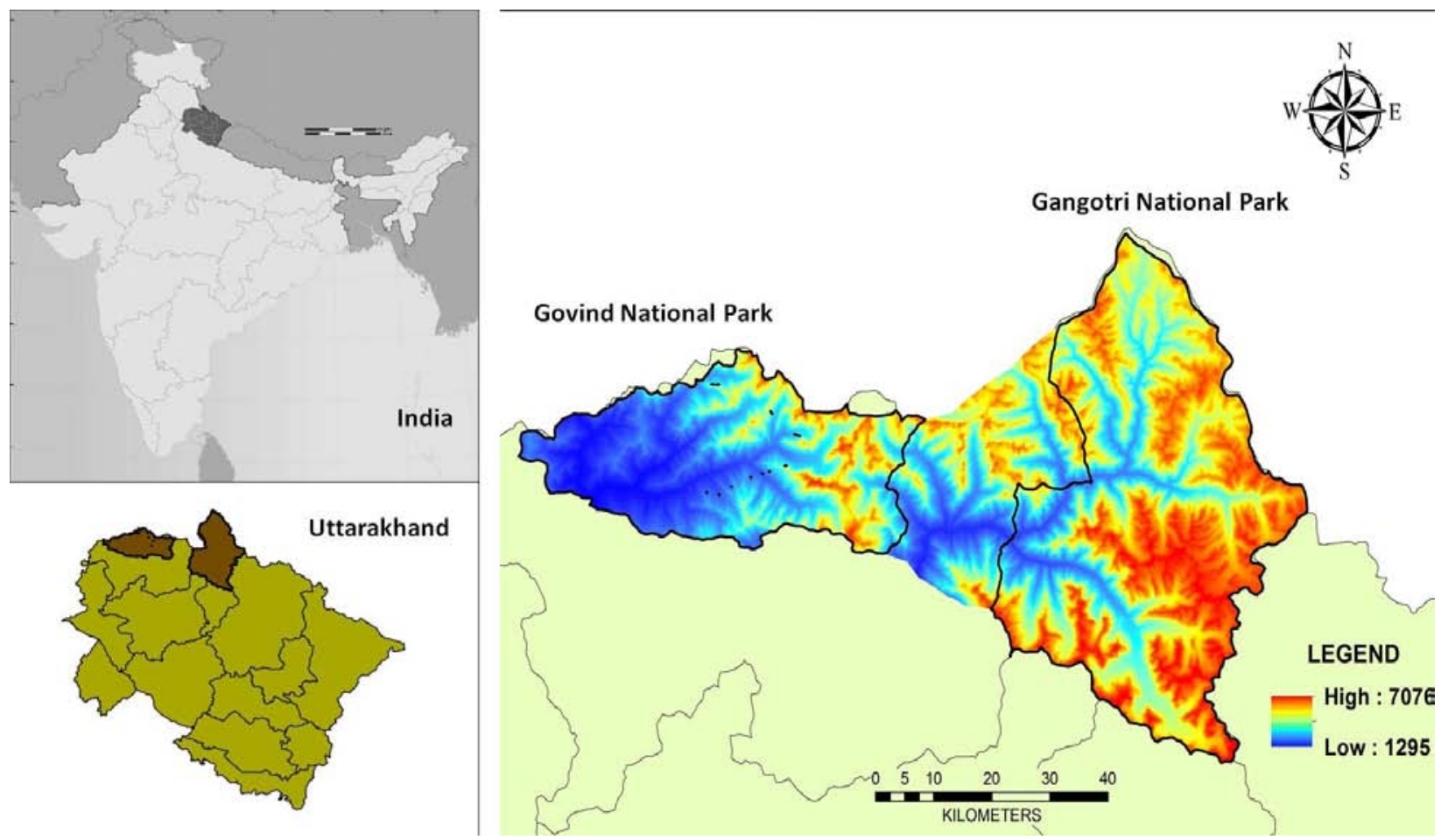

Figure 1. Digital Elevation Model of the Gangotri Landscape area showing Gangotri National Park and Govind National Park (Lowest 1295m to highest $7076 \mathrm{~m}$ altitude)

Park $\left(30^{\circ} 50^{\prime}-31^{\circ} 12^{\prime} \mathrm{N} \& 78^{\circ} 45^{\prime}-79^{\circ} 02^{\prime} \mathrm{E}\right)$ and Govind National Park $\left(31^{\circ} 02^{\prime}-31^{\circ} 20^{\prime} \mathrm{N} \& 77^{\circ} 55^{\prime}-78^{\circ} 40^{\prime} \mathrm{E}\right)$, which represents the biogeographical zone - 2B West Himalaya (Rodgers \& Panwar 1988). They are situated in Uttarkashi District of the Uttarakhand State. The altitude varies from 1200-6000 $\mathrm{m}$. The Gangotri NP covers an area of $2,390 \mathrm{~km}^{2}$ harbouring the Goumukh Glacier, the origin of the river Ganges and Govind NP covers an area of $953.12 \mathrm{~km}^{2}$ encompassing the upper catchment of river Tons. The climate of the area is typically Himalayan with medium rainfall during July-August at lower altitudes. The average rainfall is $1,500 \mathrm{~mm}$, extreme cold with three to four month snowfall in winter with permanent snowline in the higher reaches.

The vegetation pattern in the study area resembles the broad pattern of vegetational zones of northwestern Himalaya. The lower altitude represents montane subtropical type with Chir Pine (Pinus roxburghii Sarg. (Pinaceae) dominating with tree rhododendron (Rhododendron arboreum Smith (Ericaceae), Rohini (Mallotus philippensis Lam. (Euphorbiaceae), Alder (Alnus nepalensis D. Don (Betulaceae), Wild Pear (Pyrus pashia Buch.-Ham. (Rosaceae), Indian Laburnum (Cassia fistula Linn. (Caesalpiniaceae), Amla (Emblica officinalis Gaertn. Euphorbiaceae), Toon (Toona ciliata, M.J. Roem (Meliaceae). Shrub layer is dominated by Musk Rose (Rosa moschata Miller (Rosaceae),
Raspberry (Rubus sp. (Rosaceae), Wig plant (Rhus sp. (Anacardiaceae), Dodonea viscosa Linn. (Sapindaceae), Colebrooka oppositifolia Smith (Labiatae), Pyracantha crenulata M. Roemer (Rosaceae), Ziziphus mauritiana Lam. (Rhamnaceae). The mid altitude regions were represented by montane moist and dry temperate type of vegetation. Moist temperate vegetation consists of Grey Oak (Quercus leucotrichophora A. Camus (Fagaceae), Blue Pine/kail (Pinus wallichiana A.B. Jackson (Pinaceae), Western Himalayan Fir (Abies pindrow Royle (Pinaceae), Deodar (Cedrus deodara G. Don (Pinaceae), Horse Chestnut (Aesculus indica Hook. (Hippocastanaceae), Himalayan Cypress (Cupressus torulosa D. Don (Cupressaceae), and Yew (Taxus baccata Pilger (Taxaceae). The shrub layer was dominated by Viburnum continifolium D. Don (Sambucaceae), Hippophae rhamnoides Rousi (Elaeagnaceae) and Berberis sp. (Berberidaceae). The montane dry temperate vegetation zone was predominantly coniferous along with broad-leaved trees like oak, ash, maple. There were also deodar, juniper, high level fir (Abies spectabilis Mirbel. (Pinaceae) and Silver Birch (Betula utilis D. Don (Betulaceae). The subalpine zone around $3000 \mathrm{~m}$ had dense coniferous forest represented by the species like Pinus wallichiana A.B. Jackson), Himalayan Yew (Taxus wallichiana Pilger (Taxaceae)) with intermixed broad-leaved trees like Kharsu oak (Quercus 
semecarpifolia Smith (Fagaceae)). The common shrubs were Rosa webbiana Wallich (Rosaceae, Cotoneaster sp.(Rosaceae) and Berberis sp. etc. The herbaceous species like Delphinium sp.(Ranunculaceae), Swertia sp. (Gentianaceae) and Pedecularis sp. (Scrophulariaceae) were found common.

\section{Materials \& Methods}

The moths were collected using light trap running for four hours from 19:00-23:00 hr in the three seasons, viz, summer (April-May), monsoon (June-July), and post Monsoon (August-September). Wherever electricity was available, light traps were set by placing a 120W Tungsten filament bulb in front of a white 10'x 6 ' cloth sheet hung between two vertical poles in a way that it touches the surface and extends forward over the ground slightly and the data collected by this method were used for the inventory purpose, not for diversity analysis. In higher areas of subalpine zone, light traps were set by solar powered lantern which had significantly low light intensity than tungsten filament bulb. After collecting, moths were killed by Benzene vapour in killing jar. The collected specimens were processed for pinning, setting and preserved in air-tight wooden boxes. First the specimens were sorted into morphospecies. Identifications were done with the help of available literature and also by comparing with the reference collection available at Zoological Survey of India. The classification used mainly follows Hampson $(1892,1894,1895,1896)$ and subsequent changes in the families based on Kristensen (1999).

\section{Result}

Altitudinal distribution: Diversity of moth fauna in terms of morphospecies collected showed a decreasing trend along increasing altitude. For comparison between different nightly catches at different altitudes, species were collected in same season, weather condition and moon phase. The data provided in Table 1 shows the average number (total morphospecies collected/ sampling night) of moth species collected in the four

Table 1. Number of species collected in different altitude with their representative broad vegetation zones.

\begin{tabular}{|c|l|c|}
\hline Altitude (m) & Vegetation type & $\begin{array}{c}\text { Morphospecies } \\
\text { collected }\end{array}$ \\
\hline 1440 & Montane Subtropical & 76 \\
\hline 1530 & Montane Moist Temperate & 31 \\
\hline 2550 & Montane Dry Temperate & 12 \\
\hline 3450 & Subalpine & 7 \\
\hline
\end{tabular}

different altitudes with their respective broad vegetation type.

The four altitudinal zones sampled were categorized into three elevational ranges: The lower zone is represented by $500-1500 \mathrm{~m}$ which is characterized by montane subtropical and moist temperate type of forest. This zone came out as the most diverse zone (Fig. 2) in respect to moth species collected. The mid altitude zone is represented by $1500-2500 \mathrm{~m}$, which is characterized by montane dry temperate type of forest. This zone had medium diversity. The higher altitude zone is represented by $2500-3500 \mathrm{~m}$, which is characterized by subalpine vegetation. This zone contained significantly less diversity of moth species.

Seasonal variation: The data provided in Table 2 shows the total number of specimens collected in different seasons. For comparing the catch success in different season, the average value of catch success per night were used as a simple mean of total species collected by total trap nights.

Catch success was highest in summer months (AprilMay) followed by post monsoon (August-September) and monsoon (June-July) (Fig. 3).

Effect of moon phase: To observe whether the moon

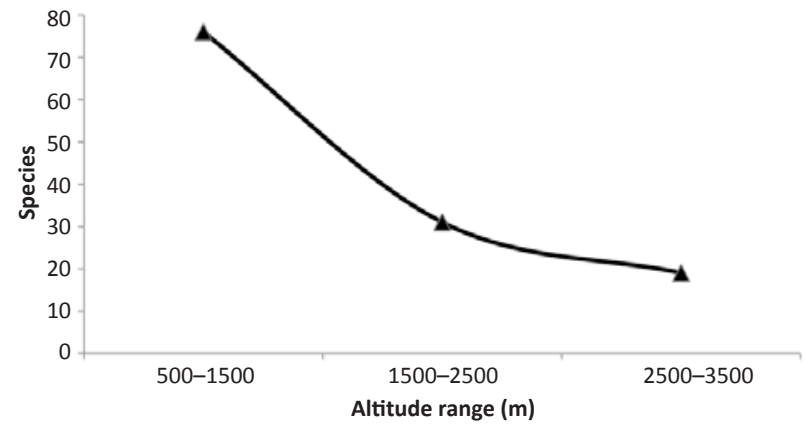

Figure 2. Trend of moth species diversity along increasing altitude.

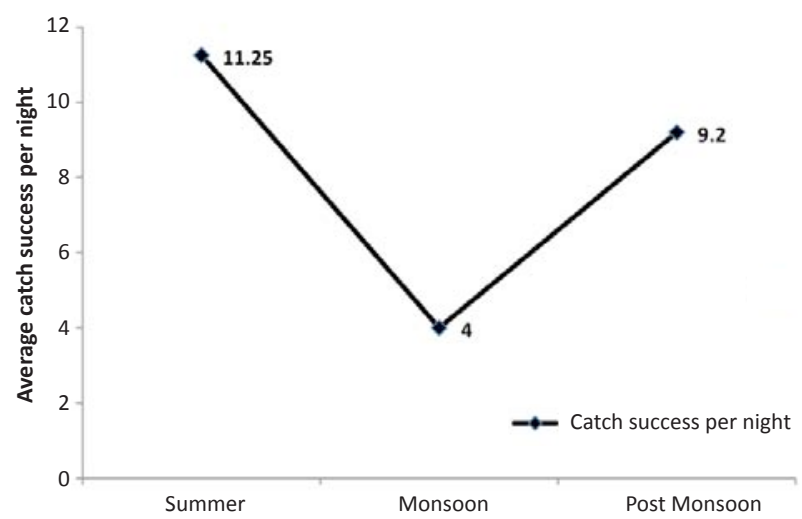

Figure 3. Catch success per night in three different seasons. 
Table 2. Species collected of moth in different seasons.

\begin{tabular}{|l|c|c|c|}
\hline Season & $\begin{array}{c}\text { Specimens } \\
\text { collected }\end{array}$ & Sampling night & $\begin{array}{c}\text { Catch success } \\
\text { per night }\end{array}$ \\
\hline Post monsoon & 65 & 7 & 9.2 \\
\hline Summer & 135 & 12 & 11.25 \\
\hline Monsoon & 8 & 2 & 4 \\
\hline
\end{tabular}

phase has any significant effect on catch success, a light trap was run on daily basis for one month period in the month of April at an altitude of 1440m from 20:0024:00 hr. The result of the observed species catch and individual catch per day in a complete lunar cycle is shown in Fig. 4. Most species as well as individuals were attracted in and around no moon nights and declined as the ambient moon light started to increase and came to a minimum around full moon nights when the ambient moon light was at its best.

Species list: Although a total of 475 specimens were collected representing 436 morphospecies in different seasons, only 32 were identified up to species rank representing six superfamilies and nine families within the short span of study time. The identified species list with their collection locality (GVNP: Govind National Park, GTNP: Gangotri National Park) and altitude at which they were collected is given in Table 3. Current valid names are provided after consulting from LepIndex (Global Lepidoptera Species Database 2007 \& The Natural History Museum, London).

\section{Discussion}

In tropical or subtropical landscapes, two patterns of diversity are typically reported on altitudinal gradients: diversity either declines (linearly or nonlinearly) with increasing altitude, or, more commonly, unimodal patterns (mid-elevation peak) are found (Rahbek 1995, 2005; McClain et al. 2007). Our study result, although a preliminary one, has indicated the previous trend, i.e., moth diversity declining linearly with increasing altitude. As the study does not cover the entire elevational range, it is hard to predict the underlying cause of such pattern. The lower altitude zone represented by montane subtropical and moist temperate type of forest is in comparatively better condition than the upper reaches, which are under pressure from increasing human settlements and grazing-related problems. The sampling related issues may also have a significant effect on this pattern as setting up light traps in lower altitude zone was easier than the alpine areas due to availability of good logistic support like electricity. Whereas in lower areas the light trap was run by tungsten filament bulb run from main power source, for sub-alpine areas solar powered light was the only feasible option with much lower intensity.

Significant seasonal variation in catch success per night was observed with the highest catch success in summer time followed by post-monsoon season and the monsoon time which had significantly lowest success. High rainfall in monsoon months resulted in low catches, suspecting that flight may be restricted in such conditions. Post-monsoon months observed a significantly high

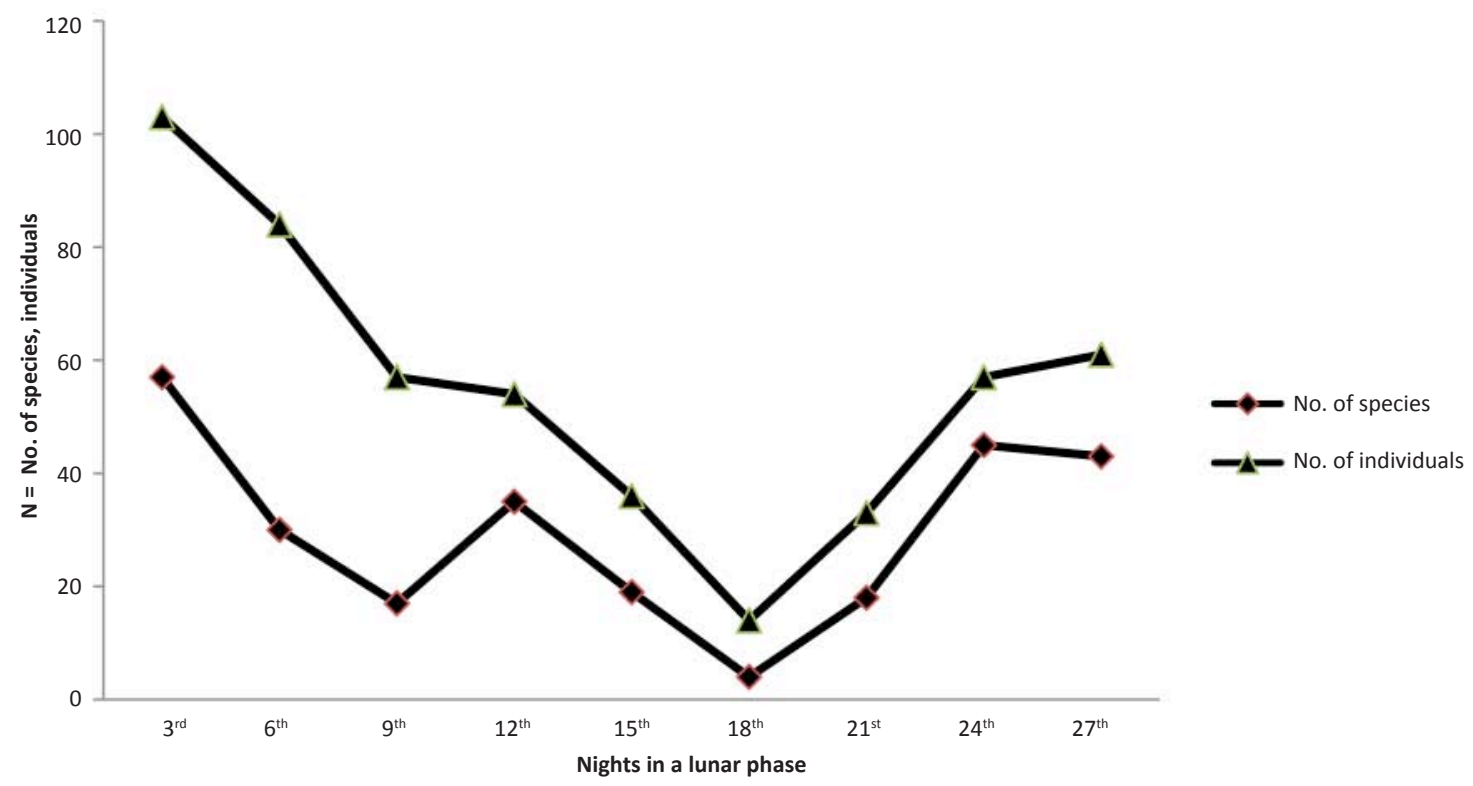

Figure 4. Effect of lunar phase on catch success. 
Table 3. Thirty two identified species with their taxonomic position and collection locality and altitude.

\begin{tabular}{|c|c|c|c|c|}
\hline Superfamily & Family & Subfamily & Species & Collected From \\
\hline \multirow[t]{4}{*}{ Pyraloidea } & Crambidae & Spilomelinae & Sameodes cancellalis Zeller & GVNP, $1440 \mathrm{~m}$ \\
\hline & & & Goniorhynchus signatalis Hampson (Image 1) & GVNP, $1440 \mathrm{~m}$ \\
\hline & & & Cirrhochrista brizoalis Walker & GVNP, GTNP, 1440m, 2550m \\
\hline & Pyralidae & Epipaschiinae & Lista haraldusalis Walker (Image 2) & GTNP, 2550m \\
\hline \multirow[t]{2}{*}{ Lasiocampoidea } & Lasiocampidae & Lasiocampinae & Trabala vishnou Lefebre & GVNP, $1440 \mathrm{~m}$ \\
\hline & & & Gastropacha pardalis Walker & GTNP, 2550m \\
\hline \multirow[t]{6}{*}{ Geometroidea } & Geometridae & Ennominae & Oxymacaria temeraria Swinhoe & GTNP, 2550m \\
\hline & & & Trichopterigia rufinotata Butler (Image 3) & GVNP, GTNP, 1530m, 2550m \\
\hline & & & Medasina albidaria Walker (Image 4) & GTNP, 3450mt \\
\hline & & & Psyra similaria Moore (Image 5) & GVNP, 1440m \\
\hline & & & Anonychia grisea Butler & GTNP, $3450 \mathrm{~m}$ \\
\hline & & Larentiinae & Photoscotosia miniosata Walker (Image 6) & GTNP, $2550 \mathrm{~m}$ \\
\hline Drepanoidea & Drepanidae & Drepaninae & Nordstromia lilacina Moore (Image 7) & GVNP, 1440m \\
\hline \multirow[t]{3}{*}{ Bombycoidea } & Sphingidae & Smerinthinae & Leucophlebia lineata Westwood (Image 8) & GTNP, GVNP, $1440 \mathrm{~m}, 2550 \mathrm{~m}, 3450 \mathrm{~m}$ \\
\hline & & Macroglossinae & Macroglossum bombylans Boisduval & GTNP, GVNP, 2550m, 3450m \\
\hline & & & Hippotion boerhaviae Fabricius & GVNP, $1440 \mathrm{~m}$ \\
\hline \multirow[t]{16}{*}{ Noctuoidea } & Lymantridae & & Lymantria concolor Walker (Image 9) & GTNP, $1530 \mathrm{~m}$ \\
\hline & Arctiidae & Lithosiinae & Macrobrochis pallens Hampson & GTNP, 1530m \\
\hline & & & Chrysorabdia bivittata Walker & GTNP, GVNP, 2550m, 1440m \\
\hline & & & Cyana horsfieldi & GVNP, $1440 \mathrm{~m}$ \\
\hline & & & Asura calamaria Moore & GTNP, $2550 \mathrm{~m}$ \\
\hline & & & Barsine gratiosa Guerin-Meneville (Image 10) & GVNP, GTNP, $1440 \mathrm{~m}, 1530 \mathrm{~m}, 2550 \mathrm{~m}$ \\
\hline & & Arctiinae & Spilosoma sp.1 & GTNP, 1530m, 2550m. \\
\hline & & & Spilosoma sp.2 & GVNP, $1440 \mathrm{~m}$ \\
\hline & & & Spilosoma sp. 3 & GVNP, GTNP, 1440m, 1550m \\
\hline & Noctuidae & Catocalinae & Catocala inconstans Butler (Image 11) & GTNP, 2550m \\
\hline & & & Dysgonia latifascia Walker & GVNP, 1440m \\
\hline & & Plusiinae & Chrysodeixis acuta Walker & GVNP, $1440 \mathrm{~m}$ \\
\hline & & & Thysanoplusia orichalcea Fabricius (Image 12) & GTNP, GVNP, 2550m, 3450m. \\
\hline & & & Erythroplusia pyropia Butler & GTNP, $2550 \mathrm{~m}$ \\
\hline & & Heliothinae & Helicoverpa armigera Hardwick & GTNP, GVNP, 1440m, 1530m, 2550m \\
\hline & & Noctuinae & Diarsia albipennis Butler (Image 13) & GTNP, GVNP, 1440m, 2550m \\
\hline
\end{tabular}

moth abundance and species richness perhaps by increased availability of fresh plant material stimulated by rain. Summer (April-May) was the best season for sampling. Moon phase or the monthly lunar cycle had a significant effect on the light trap catch success. Yela \& Holyoak (1997) from their study recommended to restrict the light trapping to periods without strong moonlight because moths are not attracted to artificial light in the presence of high ambient moonlight, though their activity remains at it's peak. Our study documented the same phenomenon where maximum number of species as well as individuals were attracted to light traps in the beginning and end of lunar cycle, i.e. from $3^{\text {rd }}$ to $6^{\text {th }}$ day and $24^{\text {th }}$ to $28^{\text {th }}$ day when there was apparently no ambient moon light. Catch success eventually dropped as the ambient moon light started to increase and became almost zero in the full moon period from $14^{\text {th }}$ to $18^{\text {th }}$ day. One factor that masked this general pattern was the presence of cloud cover evident from the slightly increased catch success in $12^{\text {th }}$ day when there was strong moon light but its effect was nullified by the clouds.

The present work gives an idea about previous and new distribution record of the 32 species mentioned 


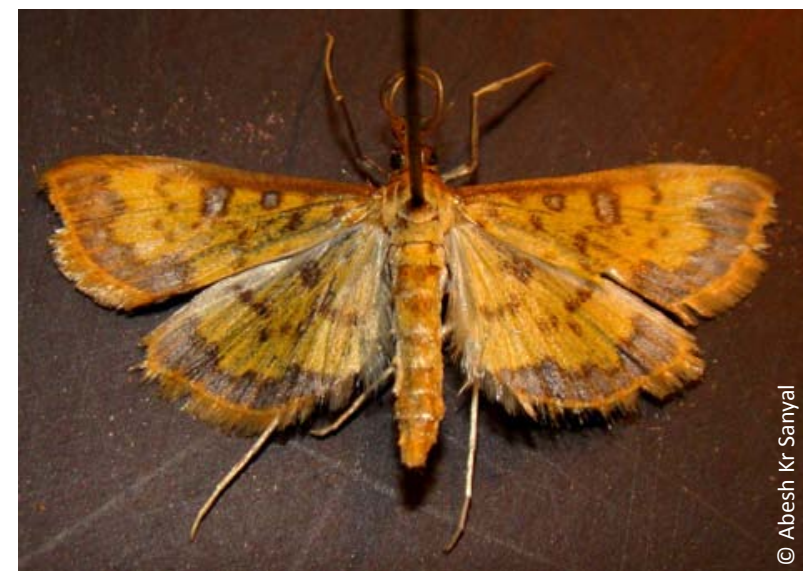

Image 1. Goniorhynchus signatalis Hampson

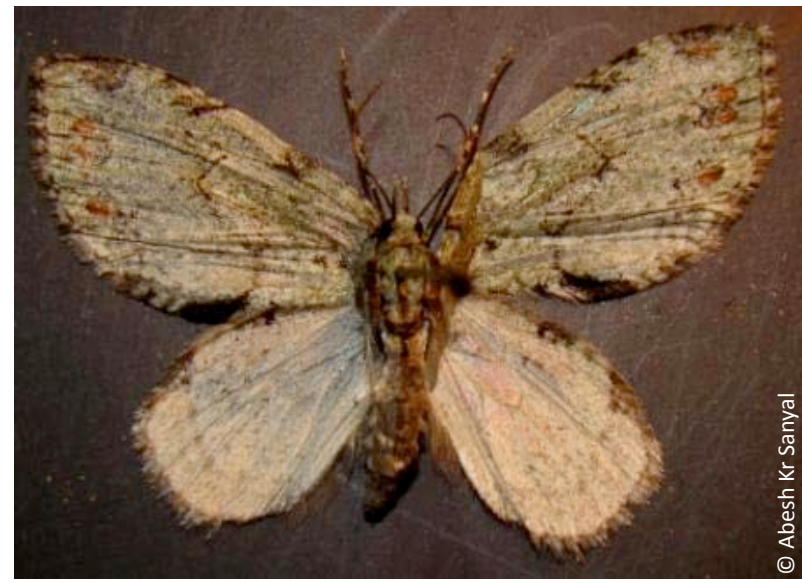

Image 3. Trichopterigia rufinotata Butler

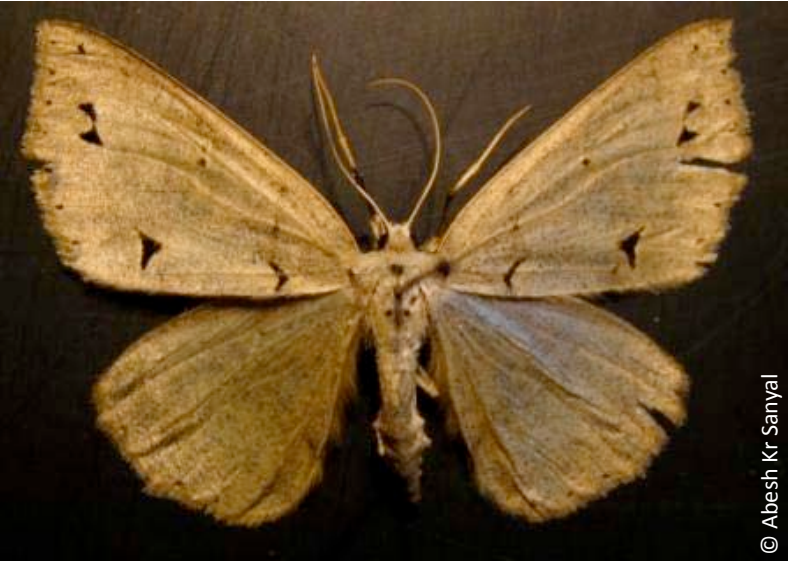

Image 5. Psyra similaria Moore

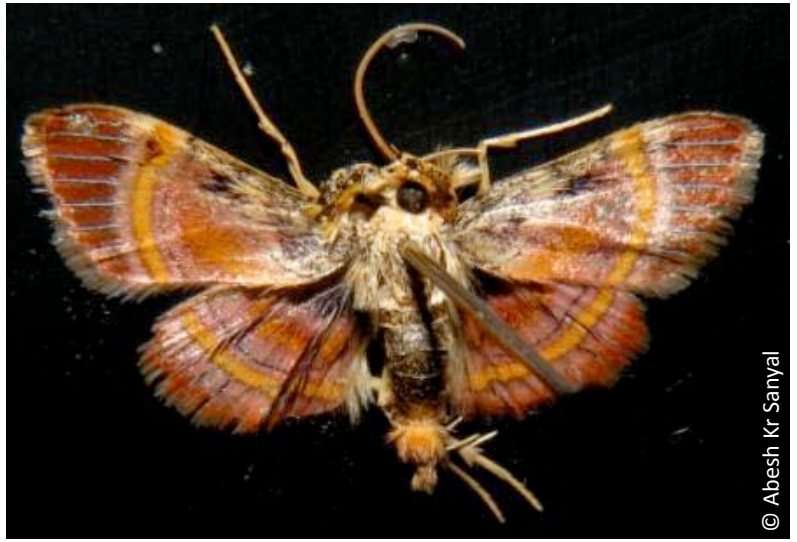

Image 2. Lista haraldusalis Walker

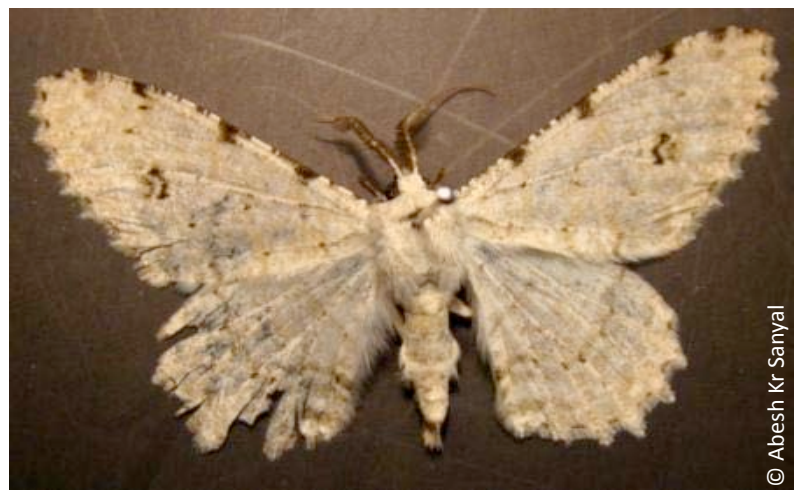

Image 4. Medasina albidaria Walker

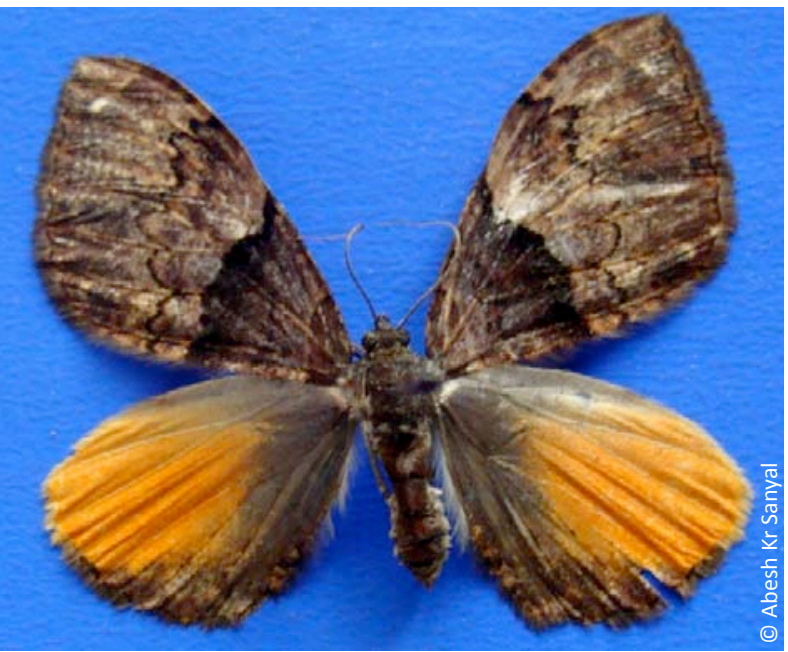

Image 6. Photoscotosia miniosata Walker 


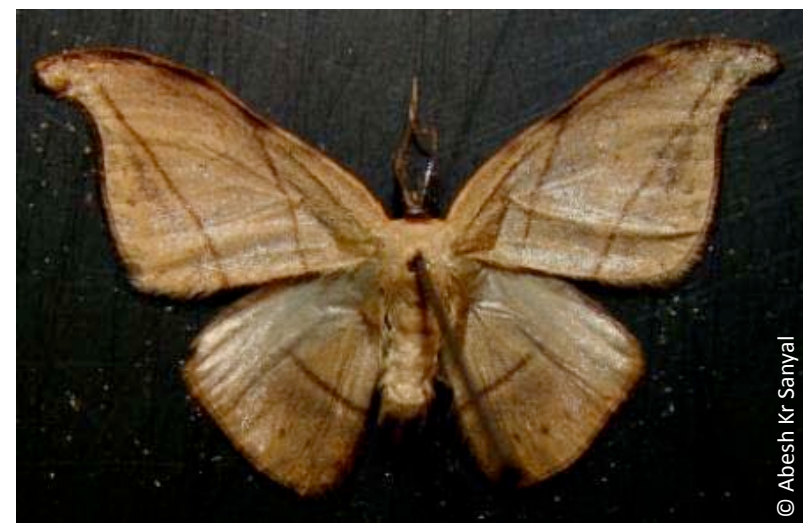

Image 7. Nordstromia lilacina Moore

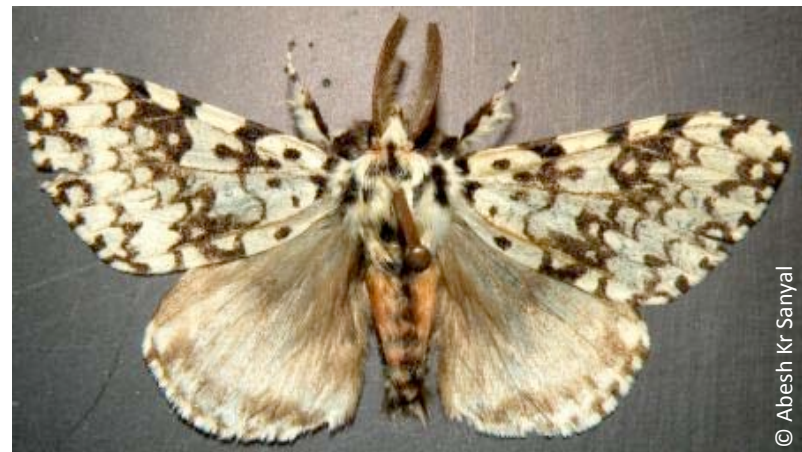

Image 9. Lymantria concolor Walker

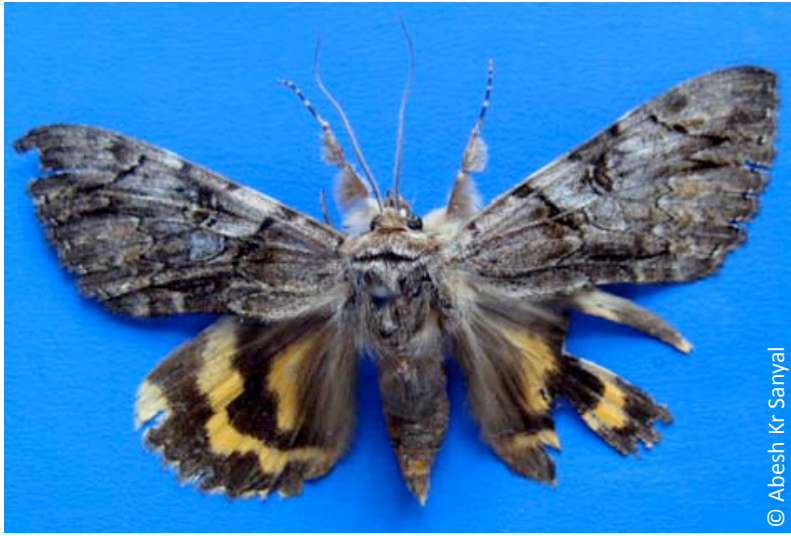

Image 11. Catocala inconstans Butler

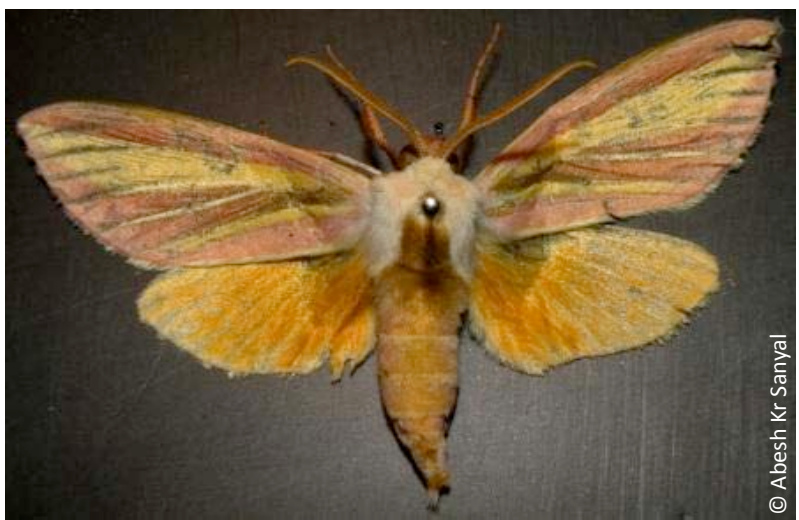

Image 8. Leucophlebia lineata Westwood

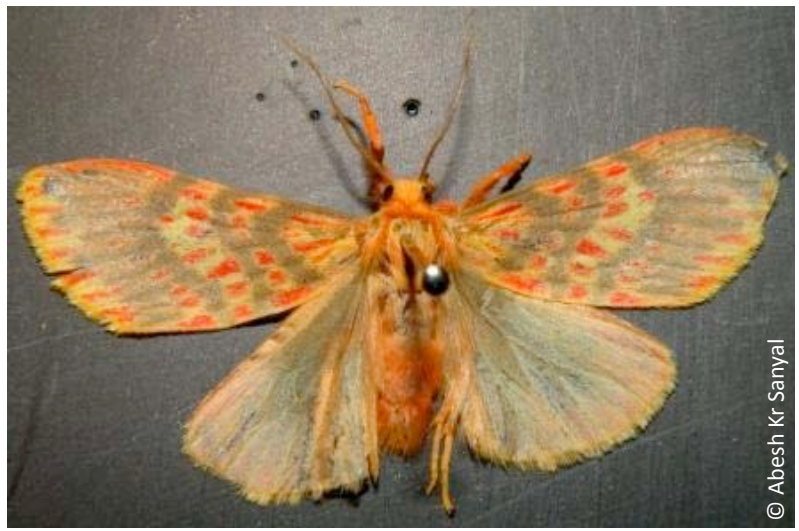

Image 10. Barsine gratiosa Guerin-Meneville

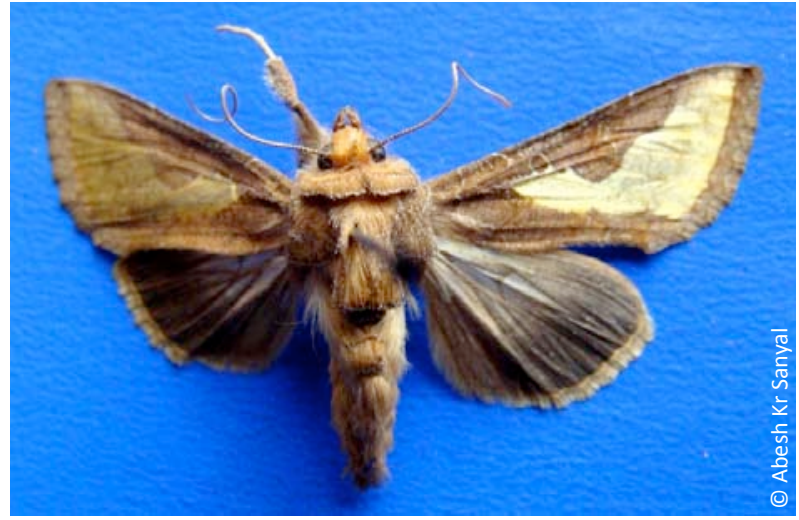

Image 12. Thysanoplusia orichalcea Fabricius 


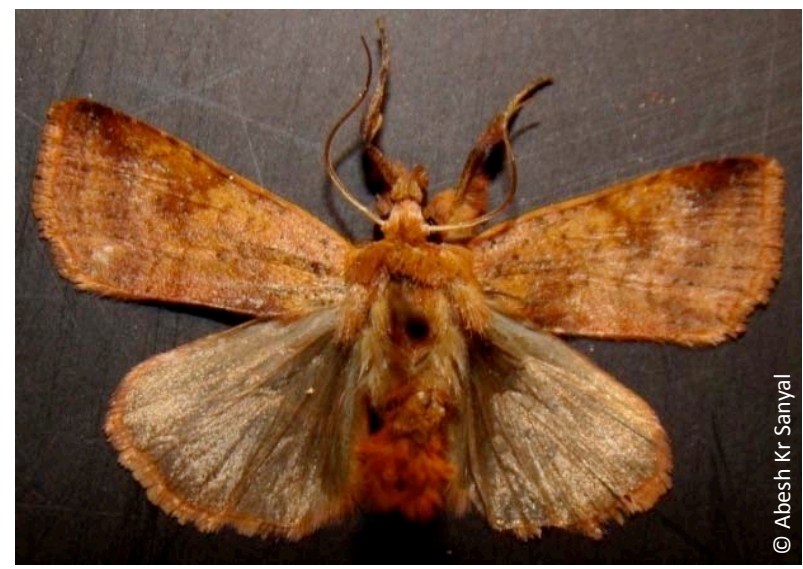

Image 13. Diarsia albipennis Butler

(Table 3). Of these, nine species are first records from Uttarakhand State, viz., Goniorhynchus signatalis, Lista haraldusalis, Trichopterigia rufinotata, Psyra similaria, Nordstromia lilacina, Spilosoma obliqua, Diarsia albipennis, Cyana horsfieldi and Spilosoma strigulata.

As the area is under tremendous pressure from the threat of loss of biodiversity due to various anthropogenic activities like increasing human population, conversion of forested land to agricultural patch, shifting cultivation and livestock grazing of pastoral people, it is very important to know about the overall picture of diversity of an important indicator group like moth calling for the need of a more thorough investigation.

\section{REFERENCES}

Arora, G.S. (1997). Insecta: Lepidoptera, pp. 67-88. In: Fauna of Conservation Area 9: Fauna of Nandadevi Biosphere Reserve.
Arora, G.S. (2000). Studies on Some Indian Pyralid Species of Economic Importance-Part 1 (Lepidoptera: Pyralidae). Zoological Survey of India, 169pp.

Bell, T.R.D \& F.B. Scott (1937). Fauna of British India: Moths-5. Dr. W. Junk B.V. Publishers, The Hague, 533pp.

Chandra, K. (2007). Moth diversity of Madhya Pradesh and Chhattisgarh, India, and its conservation measures, pp. 49-61. In: Kendrick, R.C. (ed.) Proceedings of the first South East Asian Lepidoptera Conservation Symposium, Hong Kong 2006. Kadoorie Farm \& Botanic Garden, Hong Kong.

Cotes, E.C \& C. Swinhoe (1886). A Catalogue of Moths of India. Indian Museum, 801pp.

Hampson, G.F. (1892). Fauna of British India: Moths 1. Dr. W. Junk B.V. Publishers, The Hague, 527pp.

Hampson, G.F. (1894). Fauna of British India: Moths 2, Dr. W. Junk B.V. Publishers, The Hague, 528pp.

Hampson, G.F. (1895). Fauna of British India: Moths 3, Dr. W. Junk B.V. Publishers, The Hague, 517pp.

Hampson, G.F. (1896). Fauna of British India Moths: 4, Dr. W. Junk B.V. Publishers, The Hague, 595pp.

Kristensen, N.P. (1999). Handbook of Zoology: Bd. 4. Arthropoda: Insecta. Teilbd. 35, Lepidoptera, Moths and Butterflies. Vol. 1. Evolution, Systematics, and Biogeography. W. de Gruyter, Berlin. 491pp.

Leplndex, Global Lepidoptera Species Database (2007). The Natural History Museum, London. < http://www.nhm.ac.uk/researchration/research/projects/lepindex/>. Online version dated 24 September 2010.

McClain, C.R., E.P. Ethan \& A.H. Hurlbert (2007). Challenges in the application of geometric constraints models. Global Ecology and Biogeography 16: 257-264.

Rahbek, C. (1995). The elevational gradient of specie richness: a uniform pattern? Ecography 18: 200-205.

Rahbek, C. (2005). The role of spatial scale and the perception of largescale species richness patterns. Ecology Letters 8: 224-239.

Rodgers, W. \& H.S. Panwar (1988). Wildlife Protected Areas Network in India. Wildlife Institute of India, Dehra Dun.

Smetacek, P. (2008). Moths recorded from different elevations in Nainital district, Kumaon Himalaya, India. Bionotes 10: 5-15.

Yela, J.L. \& M. Holyoak (1997). Effects of moonlight and meteorological factors on light and bait trap catches of noctuid moths (Lepidoptera: Noctuidae). Environmental Entomology 26: 1283-1290. 